\title{
Mesenchymal stem cell conditioned medium azacytidine, panobinostat and GSK126 alleviate TGF- $\beta$-induced EMT in lung cancer
}

\author{
Huihui SHEN ${ }^{1}$, Dongying $\mathrm{ZHANG}^{1}$, Hua $\mathrm{LIU}^{1 *}$
}

\begin{abstract}
This study aimed to investigate the effects of mesenchymal stem cells (MSCs) conditioned medium, azacytidine, panobinostat, and GSK126 on TGF- $\beta$-induced EMT in lung cancer. MSC were cultured in DMEM medium to make MSC conditioned medium. Our results showed that MSC conditioned medium, azacytidine, panobinostat and GSK126 reduced cell viability, invasion, expressions of $\mathrm{N}$-cad, vimentin and $\alpha$-SMA and increased E-cad expression in cells treated with TGF- $\beta$. MSC conditioned medium alleviated TGF- $\beta$-induced increases in cell viability and decrease in E-cad expression. In conclusion, MSC conditioned medium, azacytidine, panobinostat, and GSK126 could alleviate TGF- $\beta$-induced EMT in lung cancer.
\end{abstract}

Keywords: EMT; MSC conditioned medium; azacytidine; panobinostat; GSK126.

Practical Application: We investigated the effects of mesenchymal stem cells (MSCs) conditioned medium, azacytidine, panobinostat, and GSK126 on TGF- $\beta$-induced EMT in lung cancer. We found that MSC conditioned medium, azacytidine, panobinostat, and GSK126 could alleviate TGF- $\beta$-induced EMT in lung cancer.

\section{Introduction}

Lung cancer is the most common primary malignant tumor with high morbidity, rapid growth, high mortality and poor prognosis (Torre et al., 2016). Its morbidity and mortality are still the highest among all types of malignant tumors in the world (Hou et al., 1993). In addition to smoking, air pollution and genetics, occupational exposure and unhealthy diet can also lead to lung cancer (Godfrey, 2001). Therefore, lung cancer has become a serious global public health problem (Kesika et al., 2020; Wang et al., 2021; Zhao \& Zhan, 2020). In recent years, molecular targeted therapy has been a major breakthrough in the treatment of lung cancer (Dacic, 2012). However, a study found that the most cause of death in lung cancer patients was the invasion and metastasis of tumor cells (Chen et al., 2008). Hence, how to find lung cancer as soon as possible, and effectively control the invasion and metastasis of cells become an urgent problem to be solved in the treatment of lung cancer (Vasconcelos et al., 2019; Rafiq et al., 2020; Satelli \& Li, 2011).

Epithelial-mesenchymal transition (EMT) plays an important role in the invasion and metastasis of cancer cells, and the degree of malignancy in lung cancer is closely related to EMT (Jin et al., 2014; Krohn et al., 2014; Lamouille et al., 2014). EMT means that epithelial cells exhibit the characteristics of interstitial cells and acquire migration and exercise capacity, which are important for embryonic development and organ fibrosis (Zavadil et al., 2008; Lamouille et al., 2014). It is also play an important role in the occurrence and development of tumors (Jin et al., 2014). EMT can promote tumor cells infiltration and metastasis, causing tumor cells to escape apoptosis induced by certain factors (Zavadil et al., 2008; Lamouille et al., 2014). An account of studies indicates that EMT has cellular plasticity that regulate normal human tissues and tumor tissues. In addition, EMT also cause cells to form a plurality of different cell subpopulations (called cell heterogeneity) (Wahl \& Spike, 2017). These features are associated with tumor-related phenotypes, such as metastasis or mortality (Krohn et al., 2014). Therefore, designing treatment protocols based on stem cell characteristics and finding therapeutic drugs has become a hot spot in clinical research.

Mesenchymal stem cells (MSCs) are a kind of multi-potential non-hematopoietic stem cell with self-replication ability that can replenish non-active cells and repair damage to maintain the stability of the internal environment (Uccelli et al., 2008). MSCs interact with tumors by secreting a range of soluble cytokines such as vascular endothelial growth factor (VEGF) and b-fibroblast growth factor (b-FGF). MSCs not only promote EMT to increase breast cancer cell metastasis but also inhibit cell proliferation in the tumor microenvironment (Zhu et al., 2009; Martin et al., 2010). However, the mechanism by which MSC regulates EMT in lung cancer cells remains to be further elucidated.

In this study, we aimed to investigate the effects of MSC conditioned medium and three inhibitors on TGF- $\beta$-induced EMT in lung cancer and to screen effective anti-lung cancer drugs.

\section{Methods}

\subsection{Cell culture}

MSCs (HUXMA-01001) isolated from healthy adult bone marrow were purchased from Cyagen Biotechnology 
Co. Ltd (Suzhou, China) and cultured in low glucose DMEM medium supplemented with penicillin $(100 \mathrm{U} / \mathrm{mL}$, Thermo Fisher Scientific, Waltham, USA), streptomycin $(100 \mu \mathrm{g} / \mathrm{mL}$, Thermo Fisher Scientific, Waltham, USA) and 10\% (v/v) fetal calf serum (FCS; Thermo Fisher Scientific, Waltham, USA) for $48 \mathrm{~h}$ at $37^{\circ} \mathrm{C}$. The above medium was also called MSC conditioned medium.

Human lung cancer cell line A549 was purchased from ATCC (Manassas, USA), cultured in $0.1 \%$ serum for starvation overnight, and then divided into four groups: one group did not do any treatment; one group added MSC conditioned medium in equal proportion; one group added 10ng/ml TGF- $\beta$; the last one group added 1:1 MSC conditioned medium and $10 \mathrm{ng} / \mathrm{mL}$ TGF- $\beta$. In addition, each group of cells were treated with 50-200 nM GSK126 (Bio-Techne, Minnesota, USA), 5-20 nM panobinostat (Bio-Techne, Minnesota, USA) and 0.5-2 $\mu \mathrm{M}$ azacytidine (Bio-Techne, Minnesota, USA), respectively.

\subsection{Cell viability assay}

Cells (2000 cells/well) were seeded into 96-well plates for $48 \mathrm{~h}$ at $37^{\circ} \mathrm{C}$, and incubated in DMEM with $10 \mu \mathrm{L}$ MTT solution for 1-4 h. After adding dimethylsulfoxide (DMSO), the light absorption values of each well were measured at the wavelength of $450 \mathrm{nM}$ (OD450) by Enzyme-linked immunodetector (Thermo Fisher Scientific, Waltham, USA).

\subsection{Cell invasion assay}

Transwell assay was used to test cell invasion. In brief, cells were digested with trypsin (Thermo Fisher Scientific, Waltham, USA). Medium (700 $\mu \mathrm{L}$ ), including 15\% FBS (Thermo Fisher Scientific, Waltham, USA) and Matrigel (1:5; BD biosciences, California, USA), was added into the bottom membrane of Transwell chamber with extracellular matrix. Meanwhile, cell suspension was added into the upper chamber and incubated for $24 \mathrm{~h}$. Then, cells were washed three times in PBS, added $200 \mu \mathrm{L}$ of pure methanol for $15 \mathrm{~min}$, and stained with $200 \mu \mathrm{L}$ of crystal violet (Thermo Fisher Scientific, Waltham, USA) for 15 min. The stained cells were observed, counted and photographed under the microscope.

\section{4 qRT-PCR}

Total RNA was extracted by Trizol Reagent (Life Technologies Corporation, Carlsbad, USA). cDNA was reverse transcripted by TaKaRa PrimeScript II First Strand cDNA Synthesis Kit (TaKaRa Biotechnology, Dalian, China). The sequences of primers were shown in Table 1. PCR amplification system was configured by TaKaRa SYBR Premix Ex Taq II Kit (TaKaRa Biotechnology, Dalian, China) according to the specification. The conditions were $95^{\circ} \mathrm{C}$ for $10 \mathrm{~min}, 44$ cycles of $95^{\circ} \mathrm{C}$ for $10 \mathrm{~s}, 60^{\circ} \mathrm{C}$ for $20 \mathrm{~s}$, $72^{\circ} \mathrm{C}$ for $30 \mathrm{~s}$, finally $72^{\circ} \mathrm{C} 5 \mathrm{~min}$. Data were analyzed by Bio-Rad CFX Manager 1.6 Software (Bio-Rad, Hercules, CA) and $2^{-\Delta \Delta C t}$ method (Livak \& Schmittgen, 2001).

\subsection{Western blotting}

The proteins were extracted from washed cells by RIPA Lysis Buffer (Beyotime, Shanghai, China) and quantified by Coomassie
Table 1. The sequences of primers.

\begin{tabular}{ccc}
\hline Gene & F/R & Primer Sequence (5' to 3') \\
\hline E-cad & F & GGTGAAAGAGTGAGACCCCA \\
& R & GGGTCTAGGTGGGTTATGGG \\
N-cad & F & CACTTCCACCTCCACATCCT \\
& R & CTGATGACAAATAGCGGGCC \\
Vimentin & F & CCTTGGCGGGTAAGTACTCA \\
& R & TTCGTGCAATTGACCTTGGG \\
a-SMA & F & GCACGCCTATAGTCCTAGCT \\
& R & TATCGCCCTCCCACATTTGT \\
GAPDH & F & AAAAGCGGGGAGAAAGTAGG \\
& R & AAGAAGATGCGGCTGACTGT \\
\hline
\end{tabular}

F: Forward; R: Reward.

brilliant blue G-250 (Solarbio, Beijing, China). The samples were electrophoresed by SDS-PAGE and transferred to the PVDF membranes for 60-120 min. The antibody of E-cad, N-cad, Vimentine, $\alpha$-SMA and GAPDH were purchased from Abcam (Shanghai, China), diluted 3,000 times and incubated with PVDF membranes at $4{ }^{\circ} \mathrm{C}$ overnight. The secondary antibody (1: 5000, Abcam, Shanghai, China) marked by HRP was added into PVDF membranes to cultivate $1 \mathrm{~h}$ at room temperature. Then, BeyoECLPlus (Beyotime, Shanghai, China) was used to develop color in the dark, and the signals were captured and the intensity of the bands was quantified using Image $\mathrm{Lab}^{\mathrm{mt}}$ Software (Bio-Rad, Shanghai, China).

\subsection{MeDIP}

Transfected cells were digested with trypsin (Thermo Fisher Scientific, Waltham, USA), re-suspended in cold-PBS and added $870 \mu \mathrm{L}$ DNA extraction buffer, $100 \mu \mathrm{L} 10 \%$ SDS and $30 \mu \mathrm{L}$ proteinase $\mathrm{K}$ (Thermo Fisher Scientific, Waltham, USA) at $55{ }^{\circ} \mathrm{C}$ overnight. DNA was extracted by RNaseA (Thermo Fisher Scientific, Waltham, USA) $30 \mathrm{~min}$ at $37^{\circ} \mathrm{C}$. MeDIP Kit (BersinBio, Guangzhou, China) was used to perform standard MeDIP assay, and then $2 \times$ SYBR Green qPCR Mix Kit (Cwbio, Beijing, China) was used to configure the $20 \mu \mathrm{L}$ PCR amplification system following the manufacturer's instructions. Finally, data analysis was carried out to obtain enrichment efficiency.

\subsection{Statistical analysis}

The data were presented as the mean \pm standard deviation (SD), and performed using SPSS 21.0 statistical software (IBM Corporation, Armonk, USA). The p-values were calculated using student's t-test for two groups or one-way analysis of variance (ANOVA) for multiple groups. Besides, $\mathrm{p}<0.05$ was considered as statistically significant.

\section{Results}

\subsection{Effects of azacytidine, panobinostat, GSK126, MSC conditioned medium and TGF- $\beta$ on cell viability and invasion}

Firstly, in order to study the influences of MSC conditioned medium and three inhibitors azacytidine, panobinostat and GSK126 in 

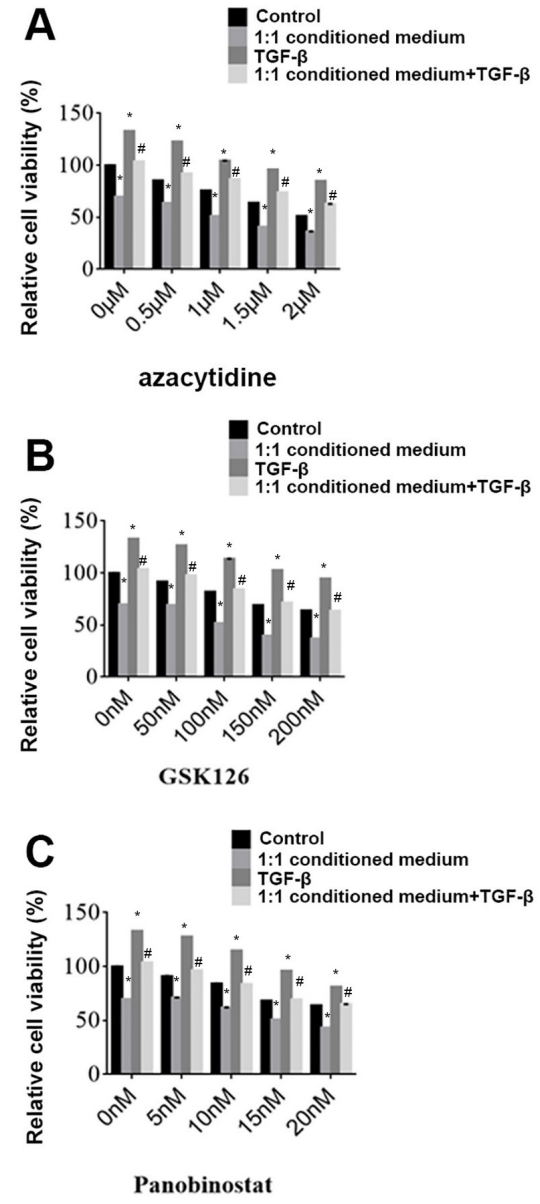

Figure 1. Effects of azacytidine, panobinostat, GSK126, MSC conditioned medium and TGF- $\beta$ on cell viability. After culturing cells, EMT cell model was established by TGF- $\beta$, and then different concentration of azacytidine, panobinostat, GSK126, MSC conditioned medium were added into different groups. MTT assay was used to detect cell viability in (A) 0, 0.5, 1.0, 1.5 and $2.0 \mu \mathrm{M}$ azacytidine; (B) 0, 50, 100, 150 and $200 \mathrm{nM}$ GSK126; (C) 0, 5, 10, 15 and $20 \mathrm{nM}$ panobinostat treated cells. ${ }^{*} \mathrm{p}<0.05$, compare with control group; $\# \mathrm{p}<0.05$, compare with the TGF- $\beta$ group.
TGF- $\beta$-induced EMT in A549 cells, we used MTT and Transwell assay to detect cell viability and invasion. In Figure 1, cell viability was significantly increased in TGF- $\beta$ treated cells, while decreased after adding 1:1 MSC conditioned medium $(\mathrm{p}<0.05)$. Besides, conditioned medium alleviated the TGF- $\beta$-induced increase in cell viability $(\mathrm{p}<0.05)$. Subsequently, Figure $1 \mathrm{~A}-\mathrm{C}$ showed that azacytidine, panobinostat and GSK126 respectively inhibited cell viability in a dose-dependent manner, respectively, but the inhibitory effect did not change significantly with increasing dose $(\mathrm{p}<0.05)$.

As shown in Figure 2 and Figure 3, relative cell count was increased in the TGF- $\beta$ group compared with that in the control group, and it was more than that in the MSC conditioned medium group $(\mathrm{p}<0.05)$. TGF- $\beta$-induced cell invasion addition was inhibited by MSC conditioned medium. Moreover, with the increase of azacytidine, panobinostat and GSK126, relative cell count was reduced in the same group $(\mathrm{p}<0.05)$. These data indicated that azacytidine, panobinostat, GSK126 and MSC conditioned medium could affect TGF- $\beta$-induced A549 cell development in lung cancer.

\subsection{Effects of azacytidine, panobinostat, GSK126, MSC conditioned medium and TGF- $\beta$ on EMT-related proteins}

Next, we explored the effects of azacytidine, panobinostat, GSK126 and MSC conditioned medium on TGF- $\beta$-induced EMT in lung cancer by qRT-PCR and western blotting. The results in Figure 4, the mRNA level of E-cad was increased in the $1: 1$ conditioned medium group, and reduced in the TGF- $\beta$ group compared with that in the control group. On the contrary, TGF- $\beta$ up-regulated and MSC conditioned medium down-regulated the mRNA levels of N-cad, Vimentin and a-SMA in A549 cells. Then, these down-regulation or up-regulation of E-cad, N-cad, Vimentin and $\alpha$-SMA were mitigated when simultaneously adding MSC conditioned medium and TGF- $\beta$. Furthermore, Figure $4 \mathrm{~A}-\mathrm{C}$ severally showed that azacytidine, panobinostat and GSK126 increased E-cad expressions and decreased N-cad, vimentin and $\alpha$-SMA expression $(\mathrm{p}<0.05)$.

In addition, western blotting results also showed that the protein level of E-cad in the control group was less

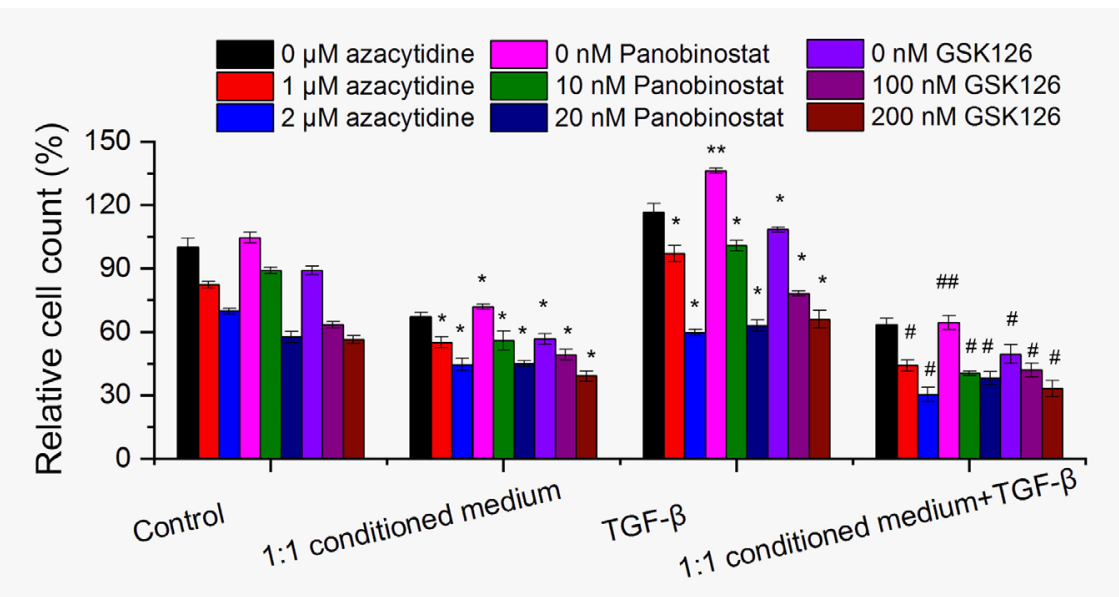

Figure 2. Effects of azacytidine, panobinostat, GSK126, MSC conditioned medium and TGF- $\beta$ on cell invasion. Transwell assay was used to detect cell invasion in cells. ${ }^{*} \mathrm{p}<0.05,{ }^{* *} \mathrm{p}<0.01$, compare with control group; $\# \mathrm{p}<0.05$, \#\# $<0.01$ compare with the TGF- $\beta$ group. 


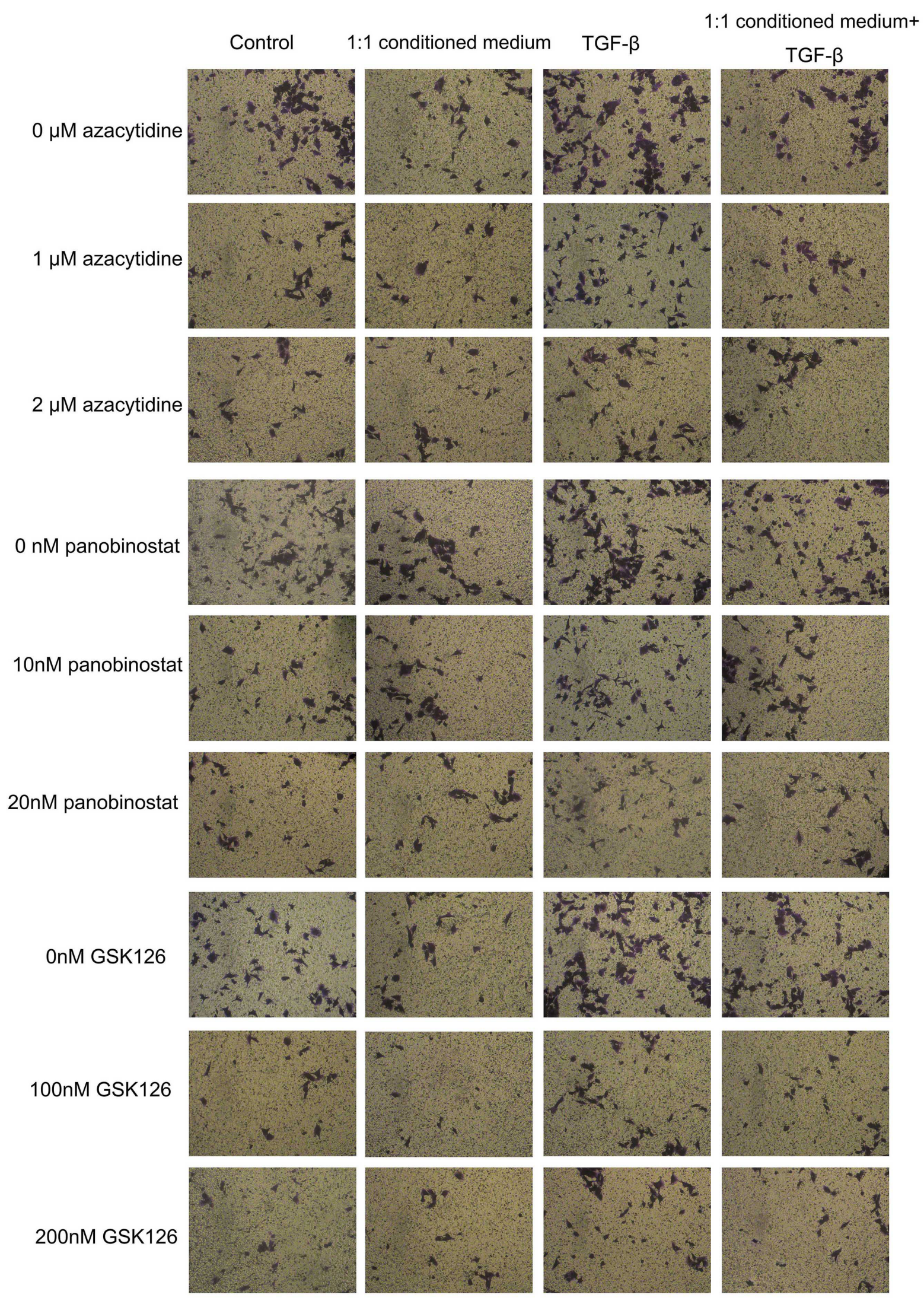

Figure 3. Effects of azacytidine, panobinostat, GSK126, MSC conditioned medium and TGF- $\beta$ on cell invasion. Transwell assay was used to detect cell invasion in cells. 
A

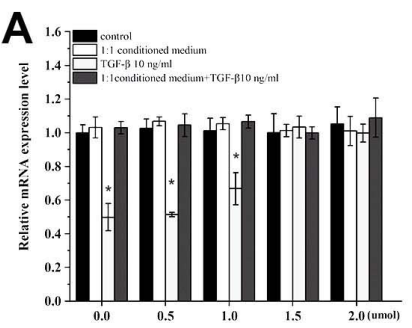

B
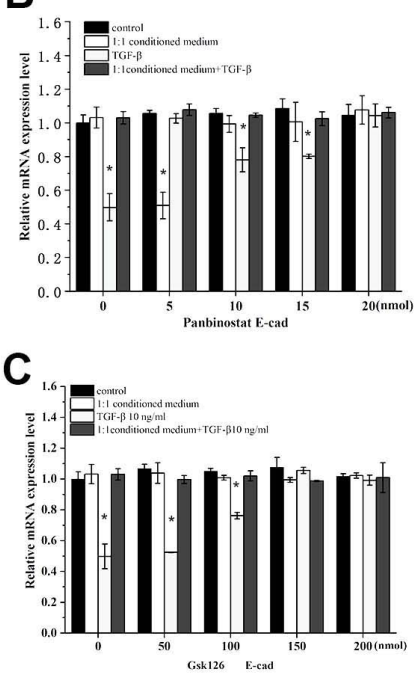

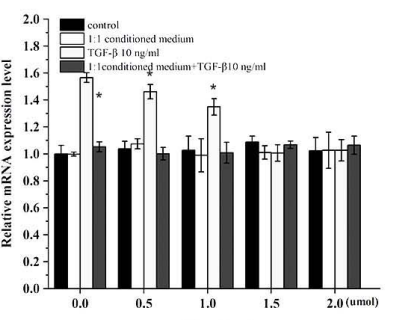

azacyditine N-cad
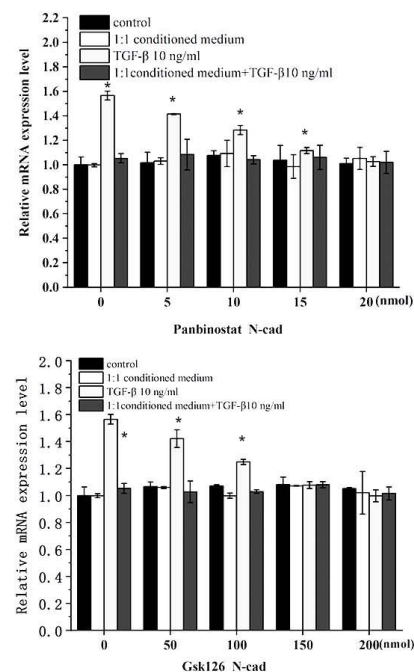
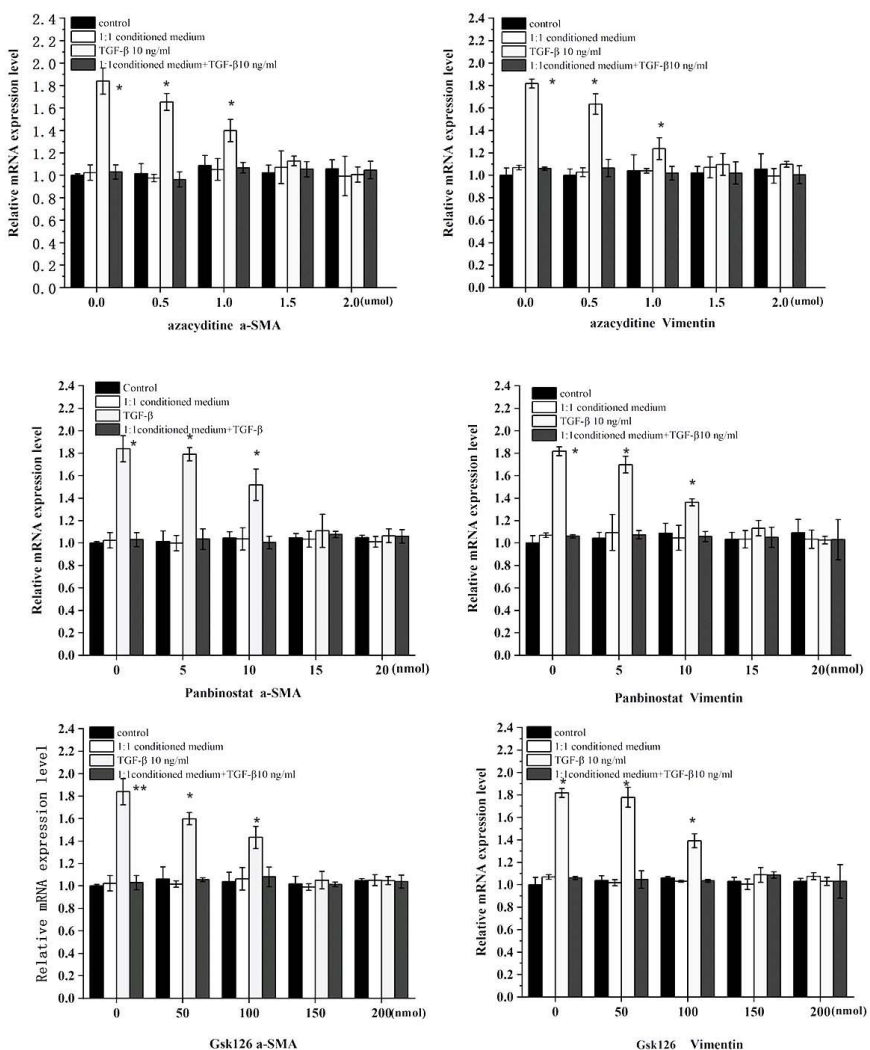

Figure 4. Effects of azacytidine, panobinostat, GSK126, MSC conditioned medium and TGF- $\beta$ on EMT-related proteins. qRT-PCR was used to assess E-cad, N-cad, Vimentin and $\alpha$-SMA in (A) 0, 0.5, 1.0, 1.5 and $2.0 \mu \mathrm{M}$ azacytidine; (B) 0, 5, 10, 15 and 20 nM Panobinostat; (C) 0, 50, 100, 150 and 200 nM GSK126 treated cells. ${ }^{*} \mathrm{p}<0.05,{ }^{* *} \mathrm{p}<0.01$, compare with control group; $\# \mathrm{p}<0.05$, \#\#p $<0.01$ compare with the TGF- $\beta$ group.

than that in the 1:1 conditioned medium group, and it was increased in the TGF- $\beta$ group. Conversely, the protein levels of $\mathrm{N}$-cad, Vimentin and $\alpha$-SMA were down-regulated when adding MSC conditioned medium, and were up-regulated in TGF- $\beta$-treated cells (Figure $5-6, p<0.05$ ). The roles of azacytidine, panobinostat and GSK126 in protein expression levels of E-cad, N-cad, Vimentin and $\alpha$-SMA were consistent with qRT-PCR results (Figure 5-6, p < 0.05). That is, E-cad expression was added and $\mathrm{N}$-cad, Vimentin and $\alpha$-SMA expressions were reduced after cells treated with azacytidine, panobinostat and GSK126.

\subsection{Effects of azacytidine, MSC conditioned medium and TGF- $\beta$ on methylation rate of EMT-related genome promoter regions}

Finally, we studied the relationship between methylation rate and EMT of lung cancer. In Figure 7, MSC conditioned medium and azacytidine reduced methylation rate of $\mathrm{E}$-cad promoter region and increased methylation rate of $\mathrm{N}$-cad, Vimentin, $\alpha$-SMA genome promoter regions. On the contrary, TGF- $\beta$ increased methylation rate of $\mathrm{E}$-cad enrichment and decreased methylation rate of $\mathrm{N}$-cad, Vimentin, $\alpha$-SMA. Besides, MSC conditioned medium alleviated the changes of TGF- $\beta$-induced methylation rate. Sum up, promoter methylation rate of E-cad,
$\mathrm{N}$-cad, Vimentin, and $\alpha$-SMA genomes were involved in the regulation of expression of such genes in lung cancer cells.

\section{Discussion}

In recent years, more and more studies have found that the invasion, metastasis and drug resistance of lung cancer are closely related to EMT (Jin et al., 2014). However, the entire EMT process is very complex. EMT can be stimulated by a variety of signaling pathways, and can also form a complex signal network with the transcription factors involved in the downstream signaling pathway of EMT in cells (Colas et al., 2012; Zaravinos, 2015).

Conditioned medium has been widely used in angiogenesis models to stimulate endothelial cells to form capillary-like structures in vitro (Lecht et al., 2014). It has been reported that MSC conditioned media protects myocardial cells from oxidative stress and reduces the severity of inflammatory arthritis and immune response (Dong, 2015; Kay et al., 2017). It may also cause neuroinflammation, exacerbate oxygen and glucose deficiencies, thereby leading to cell death (Horn et al., 2011; Khan et al., 2021; Hu et al., 2021). Ruiz et al. revealed that MSC conditioned medium can lead to proliferation or death of hepatocellular carcinoma cells, depending on the 

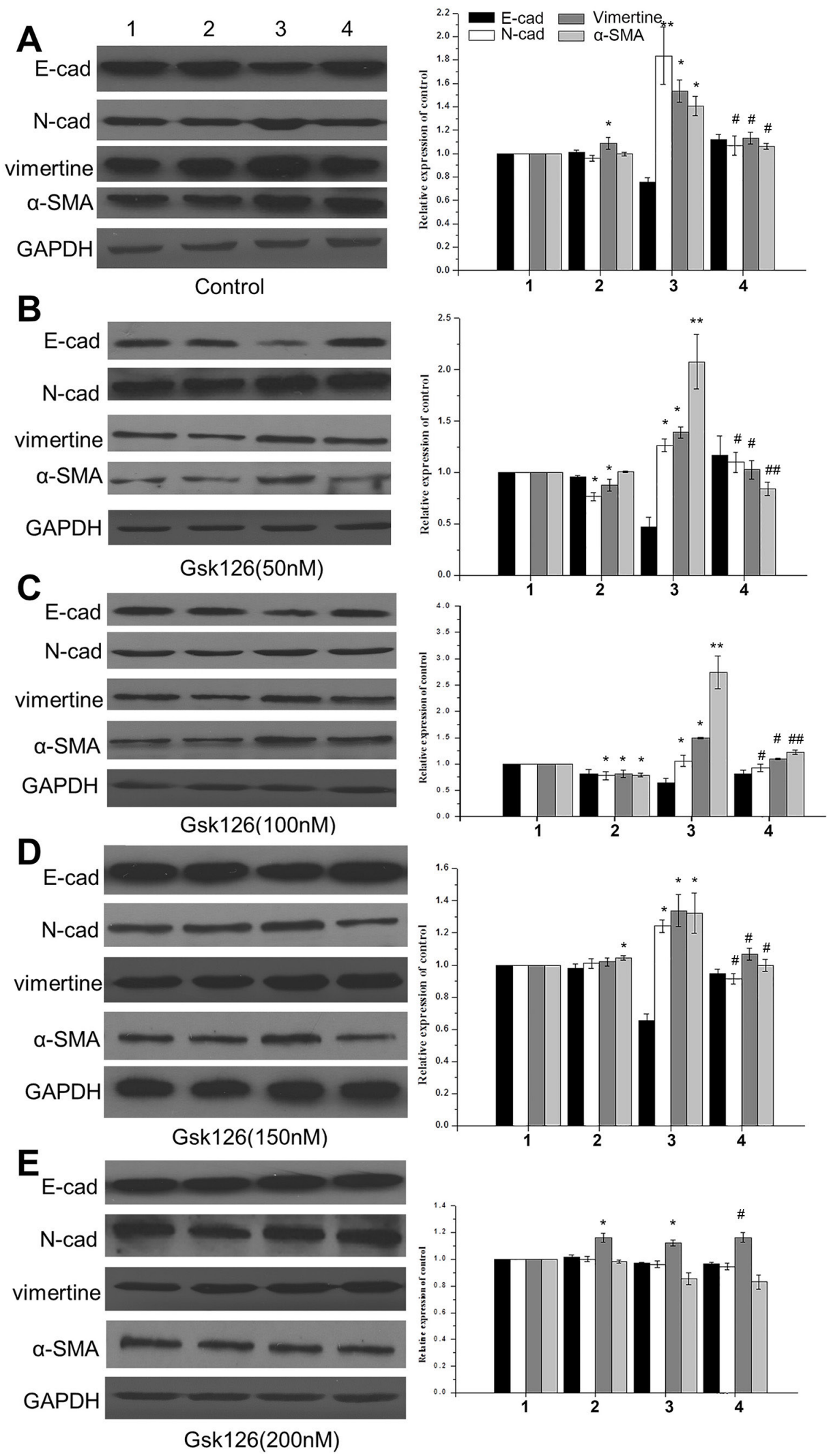

1-Control 2-1:1conditioned medium 3-TGF- $\beta$ 4-1:1 conditioned medium+TGF- $\beta$

Figure 5. Effects of GSK126, MSC conditioned medium and TGF- $\beta$ on EMT-related proteins. Western blotting was used to assess E-cad, N-cad, Vimentin and $\alpha$-SMA in 50,100, 150 and $200 \mathrm{nM}$ GSK126 treated cells. ${ }^{\star} \mathrm{p}<0.05,{ }^{* *} \mathrm{p}<0.01$, compare with control group; \#p $<0.05$, \#\#p $<$ 0.01 compare with the TGF- $\beta$ group. 


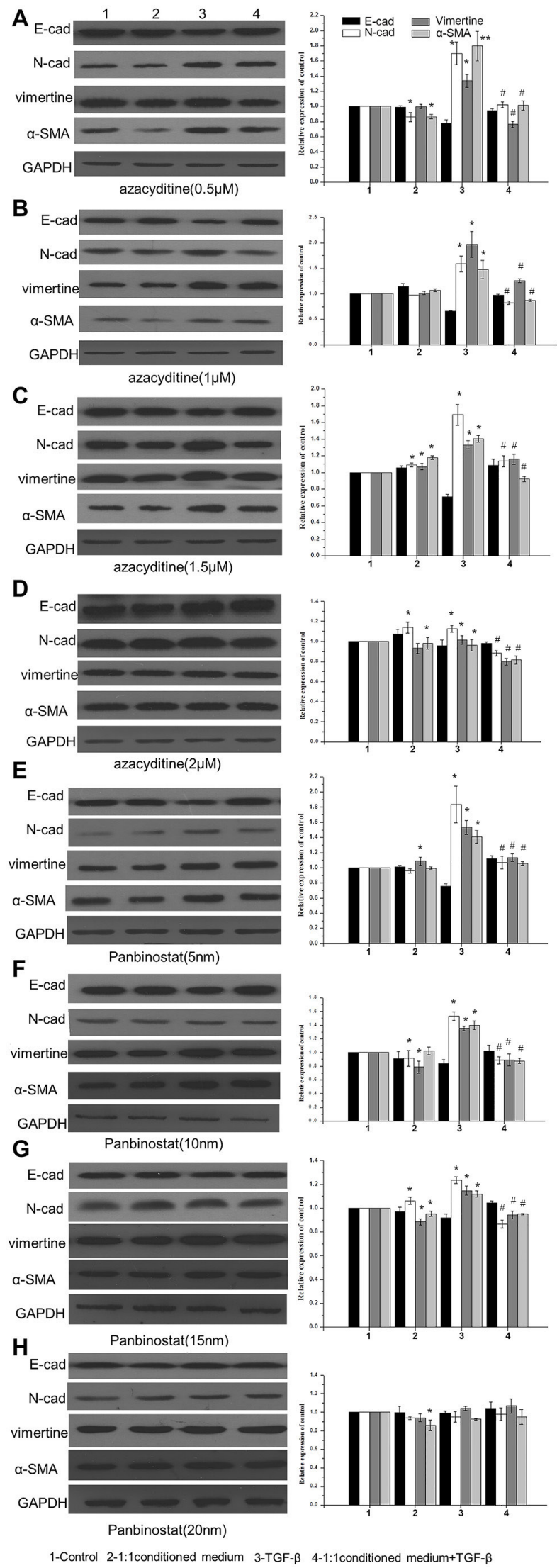

Figure 6. Effects of azacytidine and panobinostat on EMT-related proteins. Western blotting was used to assess E-cad, N-cad, Vimentin and a-SMA in (A) 0.5; (B) 1.0; (C) 1.5; (D) $2.0 \mu \mathrm{M}$ azacytidine; (E) 5; (F) 10; (G) 15; (H) $20 \mathrm{nM}$ panobinostat treated cells. ${ }^{*}$ p $<0.05$, compare with control group; $\# \mathrm{p}<0.05$, compare with the TGF- $\beta$ group. 


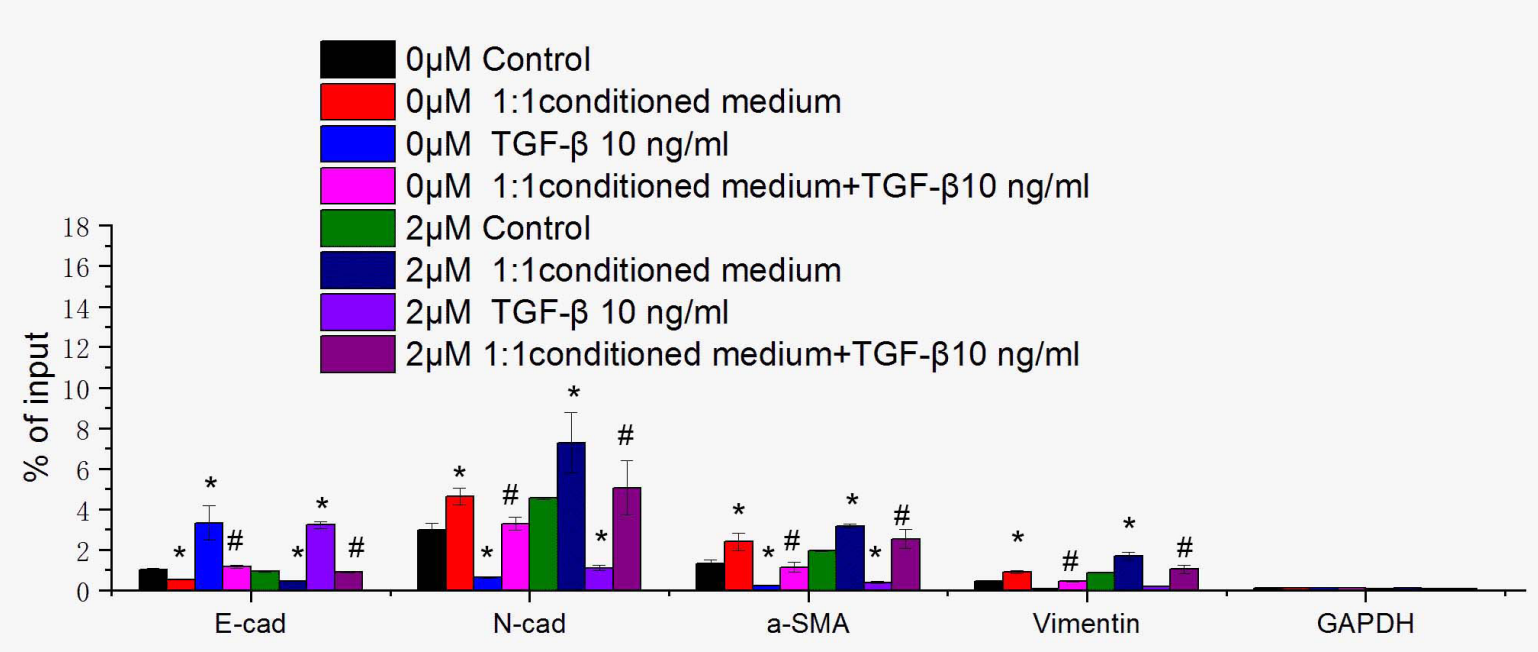

Figure 7. Effects of azacytidine, MSC conditioned medium and TGF- $\beta$ on methylation of EMT-related genome promoter regions. MeDIP was used to test the enrichment of E-cad, N-cad, Vimentin and $\alpha$-SMA methylations in 0 and $2.0 \mu \mathrm{M}$ azacytidine treated cells. ${ }^{\star} \mathrm{p}<0.05$, compare with control group; $\# \mathrm{p}<0.05$, compare with the TGF- $\beta$ group.

source of stem cells, and Maj et al. found that MSC conditioned medium may inhibit the damage caused by chemotherapy and become a potential alternative drug for urinary tract tumors (Ruiz et al., 2013; Maj et al., 2017). In this study, we found that MSC conditioned medium reduced cell viability and invasion, suggesting that MSC conditioned medium is closely related to the growth and survival of lung cancer cells.

TGF- $\beta$ is considered to be the most important factor in inducing EMT during developmental processes, cancers and other pathological conditions (Fuxe et al., 2010). In some in vitro cultured epithelial cell lines, EMT can be induced by simple TGF- $\beta$ stimulation. EMT mediated by TGF- $\beta$ signal can be achieved either through the classical Smad pathway or by the non-Smad pathway (Fuxe et al., 2010; Li et al., 2013). In this experiment, we used TGF- $\beta$ to induce the EMT process of cells. Furthermore, TGF- $\beta$ can not only inhibit the proliferation of endothelial cells, lymphocytes and hematopoietic stem cells as tumor suppressor, but also stimulate tumor fibrosis, extracellular matrix deposition and EMT process as a tumor promoting factor (Tripodo et al., 2011).

Moreover, high expressed of E-cad in early highly differentiated lung cancer cells and low expression in late poorly differentiated lung cancer suggest that the adhesion between tumor cells decreases with the down-regulation of E-cad to promote EMT occurrence (Mateen et al., 2013). Vimentin is an important factor in EMT, which is expressed more frequently in advanced lung cancer than that in early lung cancer (2011). The expression of $\mathrm{N}$-cad expression mediates the transformation of tumor cells from epithelial to mesenchymal and promotes angiogenesis (Tran et al., 1999). a-SMA can also be used as an indicator of phenotypic transformation of mesenchymal cells. It is a reliable marker protein for the cell phenotype of myofibroblasts (Ju et al., 2012). These reports indicate that the expression of these proteins is related to the malignant process of cells. In addition, Hyeonseok et al. showed that TGF- $\beta$ could induce cell morphological changes, increase cell invasion and metastasis, up-regulate the expression of N-cad, Vimentin, snail and MMP2, and down-regulate the expression of E-cad that is a classic symbol of EMT (Ko et al., 2013). And these data were similar to our experimental results, we found that TGF- $\beta$ increased cell viability, invasion, the mRNA and protein levels of $\mathrm{N}$-cad, Vimentin and $\alpha$-SMA, as well as decreased E-cad expression. At the meanwhile, TGF- $\beta$-induced changes were alleviated when cells were treated with MSC conditioned medium, indicating that MSC conditioned medium might inhibit TGF- $\beta$-induced EMT in lung cancer.

With the in-depth study of TGF- $\beta$-induced EMT in lung cancer, many inhibitors have emerged, which can effectively reverse EMT, be combined with conventional anti-tumor drugs, and reduce the risk of drug resistance of single anti-tumor drugs (Shi et al., 2015). An experiment had suggested that azacytidine can reproduce various tumor suppressor genes containing hypermethylation rate of $\mathrm{CPG}$ islands by demethylation, thereby restoring the ability to inhibit cancer (Füller et al., 2015). Hence, we chose DNA methyltransferase inhibitor azacytidine to study the mechanism of EMT in lung cancer. In addition, panobinostat increases nuclear histone and non-histone acetylation, thus regulating gene expression and protein activity associated with cancer cell growth and survival pathway (Crisanti et al., 2009). GSK126, as an EZH2 selective inhibitor, is closely related to the occurrence and development of tumors (Zeng et al., 2017; Balthazar et al., 2021). Our results showed that azacytidine, panobinostat and GSK126 respectively inhibited cell viability and invasion in a dose-dependent manner. Therefore, these suggested that we could use a higher concentration of inhibitors when avoiding EMT of lung cancer. Finally, MeDIP results also showed that MSC conditioned medium and azacytidine reduced methylation rate of $\mathrm{E}$-cad promoter region and increased methylation rate of $\mathrm{N}$-cad, Vimentin, $\alpha$-SMA genome promoter regions. Due to disordered methylation rate of DNA in animals 
can cause embryonic death, neurodegenerative diseases, some kinds of cancers, inactivation of certain genes and changes in DNA conformation in certain regions, thus affecting the interaction between proteins and DNA. Therefore, we considered that MSC conditioned medium inhibited the occurrence of EMT by removing methylation of certain genes.

In conclusion, azacytidine, panobinostat, GSK126 and MSC conditioned medium could alleviate TGF- $\beta$-induced EMT in lung cancer. These data provide an effective experimental basis for the treatment of lung cancer. However, we will study the effects and regulatory mechanisms of TGF- $\beta$ signaling pathway on EMT in lung cancer in order to find more effective anti-tumor drugs and treatments in the future.

\section{Conflict of interest}

The author declare that they have no conflict of interest.

\section{Funding}

This work supported by grants from the Specific Project of Research, Development and Promotion of Financial Technology of Guangdong Province in 2013 (No. 2060403).

\section{References}

Balthazar, C. F., Moura, N. A., Romualdo, G. R., Rocha, R. S., Pimentel, T. C., Esmerino, E. A., Freitas, M. Q., Santillo, A., Silva, M. C., Barbisan, L. F., Cruz, A. G., \& Albenzio, M. (2021). Synbiotic sheep milk ice cream reduces chemically induced mouse colon carcinogenesis. Journal of Dairy Science, 104(7), 7406-7414. http:// dx.doi.org/10.3168/jds.2020-19979. PMid:33934866.

Chen, H. W., Lee, J. Y., Huang, J. Y., Wang, C. C., Chen, W. J., Su, S. F., Huang, C. W., Ho, C. C., Chen, J. J., Tsai, M. F., Yu, S. L., \& Yang, P. C. (2008). Curcumin inhibits lung cancer cell invasion and metastasis through the tumor suppressor HLJ1. Cancer Research, 68(18), 7428-7438. http://dx.doi.org/10.1158/0008-5472.CAN-076734. PMid:18794131.

Colas, E., Pedrola, N., Devis, L., Ertekin, T., Campoy, I., Martínez, E., Llauradó, M., Rigau, M., Olivan, M., Garcia, M., Cabrera, S., GilMoreno, A., Xercavins, J., Castellvi, J., Garcia, A., Ramon y Cajal, S., Moreno-Bueno, G., Dolcet, X., Alameda, F., Palacios, J., Prat, J., Doll, A., Matias-Guiu, X., Abal, M., \& Reventos, J. (2012). The EMT signaling pathways in endometrial carcinoma. Clinical \& Translational Oncology, 14(10), 715-720. http://dx.doi.org/10.1007/ s12094-012-0866-3. PMid:22911547.

Crisanti, M. C., Wallace, A. F., Kapoor, V., Vandermeers, F., Dowling, M. L., Pereira, L. P., Coleman, K., Campling, B. G., Fridlender, Z. G., Kao, G. D., \& Albelda, S. M. (2009). The HDAC inhibitor panobinostat (LBH589) inhibits mesothelioma and lung cancer cells in vitro and in vivo with particular efficacy for small cell lung cancer. Molecular Cancer Therapeutics, 8(8), 2221-2231. http://dx.doi. org/10.1158/1535-7163.MCT-09-0138. PMid:19671764.

Dacic, S. (2012). Molecular targeted therapy of lung cancer (p. 99-107). New York: Springer.

Dong, X. (2015). MSC-conditioned medium activates Nrf2/ARE pathway to protect $\mathrm{H} 9 \mathrm{c} 2 \mathrm{cells}$ against oxidative stress. Chinese Journal of Pathophysiology, (6), 961-966

Füller, M., Klein, M., Schmidt, E., Rohde, C., Göllner, S., Schulze, I., Qianli, J., Berdel, W. E., Edemir, B., Müller-Tidow, C., \& Tschanter,
P. (2015). 5-azacytidine enhances efficacy of multiple chemotherapy drugs in AML and lung cancer with modulation of CpG methylation. International Journal of Oncology, 46(3), 1192-1204. http://dx.doi. org/10.3892/ijo.2014.2792. PMid:25501798.

Fuxe, J., Vincent, T., \& Herreros, A. G (2010). Transcriptional crosstalk between TGFbeta and stem cell pathways in tumor cell invasion: role of EMT promoting Smad complexes. Cell Cycle, 9(12), 2363-2374. http://dx.doi.org/10.4161/cc.9.12.12050. PMid:20519943.

Godfrey, C. (2001). The economic and social costs of lung cancer and the economics of smoking prevention. Monaldi Archives for Chest Disease, 56(5), 458-461. PMid:11887505.

Horn, A. P., Bernardi, A., Frozza, R. L., Grudzinski, P. B., Hoppe, J. B., de Souza, L. F., Chagastelles, P., Wyse, A. T. S., Bernard, E. A., Battastini, A. M., Campos, M. M., Lenz, G., Nardi, N. B., \& Salbego, C. (2011). Mesenchymal stem cell-conditioned medium triggers neuroinflammation and reactive species generation in organotypic cultures of rat hippocampus. Stem Cells and Development, 20(7), 1171-1181. http://dx.doi.org/10.1089/scd.2010.0157. PMid:20955077.

Hou, Q., Wang, Q., Bai, X., Wang, J., \& Dong, S. (1993). Analysis of lung cancer incidence and mortality in Tianjin. Chinese Journal of Cancer Research, 5(3), 165-169. http://dx.doi.org/10.1007/BF02997516.

Hu, J. X., Gao, J. Y., Zhao, Z. J., \& Yang, X. (2021). Response surface optimization of polysaccharide extraction from galla chinensis and determination of its antioxidant activity in vitro. Food Science Technology, 41(1), 188-194. http://dx.doi.org/10.1590/fst.38619.

Jin, Y., Li, F., Zheng, C., Wang, Y., Fang, Z., Guo, C., Wang, X., Liu, H., Deng, L., Li, C., Wang, H., Chen, H., Feng, Y., \& Ji, H. (2014). NEDD9 promotes lung cancer metastasis through epithelial-mesenchymal transition. International Journal of Cancer, 134(10), 2294-2304. http://dx.doi.org/10.1002/ijc.28568. PMid:24174333.

Ju, W., Zhihong, Y., Zhiyou, Z., Qin, H., Dingding, W., Li, S., Baowei, Z., Xing, W., Ying, H., \& An, H. (2012). Inhibition of a-SMA by the ectodomain of FGFR2c attenuates lung fibrosis. Molecular Medicine, 18(1), 992-1002. http://dx.doi.org/10.2119/molmed.2011.00425. PMid:22451267.

Kay, A. G., Long, G., Tyler, G., Stefan, A., Broadfoot, S. J., Piccinini, A. M., Middleton, J., \& Kehoe, O. (2017). Mesenchymal stem cell-conditioned medium reduces disease severity and immune responses in inflammatory arthritis. Scientific Reports, 7(1), 18019. http://dx.doi.org/10.1038/s41598-017-18144-w. PMid:29269885.

Kesika, P., Sivamaruthi, B., \& Chaiyasut, C. (2020). Health promoting effects of fermented foods against cancer: an updated concise review. Food Science Technology, 42(1), 1-9. http://dx.doi.org/10.1590/fst.18220.

Khan, M. A., Amir, R. M., Ameer, K., Rakha, A., Faiz, F., Hayat, I., Nadeem, M., Ahmed, Z., Riaz, A., \& Ashraf, I. (2021). Characterization of oat bran B-glucan with special reference to efficacy study to elucidate its health claims for diabetic patients. Food Science Technology, 41(1), 105-112. http://dx.doi.org/10.1590/fst.39019.

Ko, H., So, Y., Jeon, H., Jeong, M. H., Choi, H. K., Ryu, S. H., Lee, S. W., Yoon, H. G., \& Choi, K. C. (2013). TGF- $\beta 1$-induced epithelialmesenchymal transition and acetylation of Smad2 and Smad3 are negatively regulated by EGCG in human A549 lung cancer cells. Cancer Letters, 335(1), 205-213. http://dx.doi.org/10.1016/j. canlet.2013.02.018. PMid:23419524.

Krohn, A., Ahrens, T., Yalcin, A., Plönes, T., Wehrle, J., Taromi, S., Wollner, S., Follo, M., Brabletz, T., Mani, S. A., Claus, R., Hackanson, B., \& Burger, M. (2014). Tumor cell heterogeneity in Small Cell Lung Cancer (SCLC): phenotypical and functional differences associated with Epithelial-Mesenchymal Transition (EMT) and DNA methylation changes. PLoS One, 9(6), e100249. http://dx.doi. org/10.1371/journal.pone.0100249. PMid:24959847. 
Lamouille, S., Xu, R., \& Derynck, R. (2014). Molecular mechanisms of epithelial-mesenchymal transition. Nature Reviews. Molecular Cell Biology, 15(3), 178-196. http://dx.doi.org/10.1038/nrm3758. PMid:24556840.

Lecht, S., Gerstenhaber, J. A., Stabler, C. T., Pimton, P., Karamil, S., Marcinkiewicz, C., Schulman, E. S., \& Lelkes, P. I. (2014). Heterogeneous mixed-lineage differentiation of mouse embryonic stem cells induced by conditioned media from a549 cells. Stem Cells and Development, 23(16), 1923-1936. http://dx.doi.org/10.1089/ scd.2014.0042. PMid:24720740.

Li, R., Wang, Y., Liu, Y., Chen, Q., Fu, W., Wang, H., Cai, H., Peng, W., \& Zhang, X. (2013). Curcumin Inhibits Transforming Growth Factor- $\beta 1$-Induced EMT via PPAR $\gamma$ pathway, not smad pathway in renal tubular epithelial cells. PLoS One, 8(3), e58848. http://dx.doi. org/10.1371/journal.pone.0058848. PMid:23544048.

Livak, K. J., \& Schmittgen, T. D. (2001). Analysis of relative gene expression data using real-time quantitative PCR and the 2(-Delta Delta C(T)) method. Methods, 25(4), 402-408. http://dx.doi. org/10.1006/meth.2001.1262. PMid:11846609.

Maj, M., Bajek, A., Nalejska, E., Porowinska, D., Kloskowski, T., Gackowska, L., \& Drewa, T. (2017). Influence of mesenchymal stem cells conditioned media on proliferation of urinary tract cancer cell lines and their sensitivity to ciprofloxacin. Journal of Cellular Biochemistry, 118(6), 1361-1368. http://dx.doi.org/10.1002/ jcb.25794. PMid:27873362.

Martin, F. T., Dwyer, R. M., Kelly, J., Khan, S., Murphy, J. M., Curran, C., Miller, N., Hennessy, E., Dockery, P., Barry, F. P., O’Brien, T., \& Kerin, M. J. (2010). Potential role of mesenchymal stem cells (MSCs) in the breast tumour microenvironment: stimulation of epithelial to mesenchymal transition (EMT). Breast Cancer Research and Treatment, 124(2), 317-326. http://dx.doi.org/10.1007/s10549-0100734-1. PMid:20087650.

Mateen, S., Raina, K., Agarwal, C., Chan, D., \& Agarwal, R. (2013). Silibinin synergizes with histone deacetylase and DNA methyltransferase inhibitors in upregulating E-cadherin expression together with inhibition of migration and invasion of human non-small cell lung cancer cells. The Journal of Pharmacology and Experimental Therapeutics, 345(2), 206-214. http://dx.doi.org/10.1124/jpet.113.203471. PMid:23461975.

Rafiq, S., Gulzar, N., Huma, N., Hussain, I., \& Murtaza, M. S. (2020). Evaluation of anti-proliferative activity of Cheddar cheeses using colon adenocarcinoma (HCT-116) cell line. International Journal of Dairy Technology, 73(1), 255-260. http://dx.doi.org/10.1111/1471-0307.12665.

Ruiz, J. L., Levy, D., Carvalho, A. C., Sekiya, E., \& Bydlowski, S. (2013). Conditioned medium from human mesenchymal stem cells (MSC) from different sources induce proliferation or cell death in HepG-2 and Jurkat cancer cells depending on its origin. Experimental Hematology, 41(8), S75. http://dx.doi.org/10.1016/j.exphem.2013.05.293.

Satelli, A., \& Li, S. (2011). Vimentin in cancer and its potential as a molecular target for cancer therapy. Cellular and Molecular Life Sciences, 68(18), 3033-3046.

Shi, H., Ji, Y., Zhang, D., Liu, Y., \& Fang, P. (2015). MiR-135a inhibits migration and invasion and regulates EMT-related marker genes by targeting KLF8 in lung cancer cells. Biochemical and Biophysical Research Communications, 465(1), 125-130. http://dx.doi.org/10.1016/j. bbrc.2015.07.145. PMid:26235874.

Torre, L. A., Siegel, R. L., \& Jemal, A. (2016). Lung cancer statistics. Advances in Experimental Medicine and Biology, 893, 1-19. http:// dx.doi.org/10.1007/978-3-319-24223-1_1. PMid:26667336.

Tran, N. L., Nagle, R. B., Cress, A. E., \& Heimark, R. L. (1999). $\mathrm{N}$-cadherin expression in human prostate carcinoma cell lines: an epithelial-mesenchymal transformation mediating adhesion with stromal cells. The American Journal of Pathology, 155(3), 787-798. http://dx.doi.org/10.1016/S0002-9440(10)65177-2. PMid:10487836.

Tripodo, C., Sangaletti, S., Piccaluga, P. P., Prakash, S., Franco, G., Borrello, I., Orazi, A., Colombo, M. P., \& Pileri, S. A. (2011). The bone marrow stroma in hematological neoplasms--a guilty bystander. Nature Reviews. Clinical Oncology, 8(8), 456-466. http://dx.doi. org/10.1038/nrclinonc.2011.31. PMid:21448151.

Uccelli, A., Moretta, L., \& Pistoia, V. (2008). Mesenchymal stem cells in health and disease. Nature Reviews. Immunology, 8(9), 726-736. http://dx.doi.org/10.1038/nri2395. PMid:19172693.

Vasconcelos, F. M., Silva, H. L. A., Poso, S. M. V., Barroso, M. V., Lanzetti, M., Rocha, R. S., Graça, J. S., Esmerino, E. A., Freitas, M. Q., Silva, M. C., Raices, R. S. L., Granato, D., Pimentel, T. C., Sant'Ana, A. S., Cruz, A. G., \& Valença, S. S. (2019). Probiotic Prato cheese attenuates cigarette smoke-induced injuries in mice. Food Research International, 123, 697-703. http://dx.doi.org/10.1016/j. foodres.2019.06.001. PMid:31285019.

Wahl, G. M., \& Spike, B. T. (2017). Cell state plasticity, stem cells, EMT, and the generation of intra-tumoral heterogeneity. NPJ Breast Cancer 3(1), 14. http://dx.doi.org/10.1038/s41523-017-0012-z. PMid:28649654.

Wang, Y. X., Wang, L., Guo, J., Wang, Z. Y., Hua, S. C. (2021). The efficacy and safety of endostar combined gemcitabine and cisplatin in the treatment of non-small cell lung cancer: a meta-analysis. Food Science Technology, (1), 1-13.

Zaravinos, A. (2015). The regulatory role of microRNAs in EMT and cancer. Journal of Oncology, 2015, 865816. http://dx.doi. org/10.1155/2015/865816. PMid:25883654.

Zavadil, J., Haley, J., Kalluri, R., Muthuswamy, S. K., \& Thompson, E. (2008). Epithelial-mesenchymal transition. Cancer Research, 68(23), 9574-9577. http://dx.doi.org/10.1158/0008-5472.CAN-08-2316. PMid:19047131.

Zeng, D., Liu, M., \& Pan, J. (2017). Blocking EZH2 methylation transferase activity by GSK126 decreases stem cell-like myeloma cells. Oncotarget, 8(2), 3396-3411. http://dx.doi.org/10.18632/ oncotarget.13773. PMid:27926488.

Zhao, M., \& Zhan, Q. Q. (2020). Rehabilitation treatment of enteral nutrition whey protein in lung cancer patients in southern China. Food Science Technology, (4), 1-6.

Zhu, Y., Sun, Z., Han, Q., Liao, L., Wang, J., Bian, C., Li, J., Yan, X., Liu, Y., Shao, C., \& Zhao, R. C. (2009). Human mesenchymal stem cells inhibit cancer cell proliferation by secreting DKK-1. Leukemia, 23(5), 925-933. http://dx.doi.org/10.1038/leu.2008.384. PMid:19148141. 